\title{
Correspondence
}

\section{A simple device for improving patient comfort}

To the Editor:

Chronic back pain is common during pregnancy and particularly in the peripartum period. Crawford ' reported a 45 per cent incidence following epidural block for labour, while Grove ${ }^{2}$ found an incidence of 40 per cent following spontaneous vaginal delivery (non-epidural). Backache occurs irrespective of the mode of delivery (spontaneous or operative) and irrespective of the use of regional analgesia/anaesthesia. The physiological changes of pregnancy that probably contribute to this problem include: weight gain, a protruberant abdomen, stretched abdominal muscles and hormonally relaxed softening of the spinous ligaments - all of which lead to a progressive lumbar lordosis. ${ }^{3}$ During labour and delivery, this situation may be aggravated by both the presentation of the fetus and by the positioning of the mother. Caesarean section parturients are positioned supine, which accentuates the lumbar lordosis.

Patients who require a Caesarean section will frequently position themselves on the operating table with their knees flexed, until the nurse or physician instructs them to straighten them in order to position a restraint. Because of this apparent position of comfort (flexion of the knees) and the observation that patients with symptoms of back pain are more comfortable with the knees flexed, a practice of inserting a pillow under the knees of all Caesarean section patients was initiated at the Grace Hospital. Patients responded by commenting on their increased comfort with this simple measure.

A bolster was subsequently designed for use under the knees (see photo). It is now part of the routine for all patients having a Caesarean section to have this positioned immediately on turning the patient to the supine position. This includes those having regional anaesthesia and those having general anaesthesia. The bolster design and dimensions are shown in the Figure. A formal study has not been undertaken to demonstrate improved patient comfort, but the overall impression has been that this has been a positive step.

Although the pregnant patient is at particular risk to develop backache, we would suggest that this device is applicable in the general operating theatre. Patients who are required to be in the supine position for long surgical procedures, in particular, would benefit from this. The

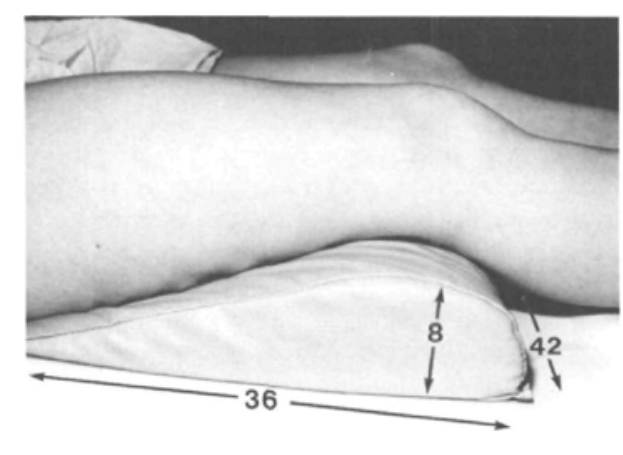

FIGURE Photograph of patient with wedge in place

only contraindication to its use would be interference with the surgical site. A recent study by Donovan et $a l^{4}$ reported on the use of an inflatable wedge to support the lumbosacral curve in patients having surgery in the supine or lithotomy position. They found a significant reduction in the incidence of postoperative backache. A bolster such as we have described is an alternative to this and if this is not available, a pillow may be used. We would suggest that more attention should be paid to the potential problem of backache in both the obstetric and surgical population.

\section{Joanne Douglas MD FRCPC}

Peggy L.E. Ross MD B SCM FRCPC

E.C. Olsen RN

Division of Obstetric Anaesthesia

The University of British Columbia and

Grace Hospital

4490 Oak Street

Vancouver, BC, V6H 3 V5

\section{REFERENCES}

1 Crawford $J S$. Lumbar epidural block in labour: a clinical analysis. Br J Anaesth 1972; 44: 66-74.

2 Grove $L H$. Backache, headache and bladder dysfunction after delivery. Br J Anaesth 1973; 45: 1 147-9.

3 Warren TM. Fletcher $M$. Anesthetic management in neurologic disease. In: Clinics in Anesthesiology 1986; 4: 301 .

$4 O^{\prime}$ Donovan N, Healy TEJ, Faragher EB, Wilkins RG Hamilion AA. Postoperative backache: the use of an inflatable wedge. Br J Anaesth 1986; 58: 280-3. 